\title{
Analise econômica para implantação de um porto fluvial no município de Porto Nacional/TO
}

Os portos são considerados como uma das instalações mais importantes para a infraestrutura de transporte nacional, com isso o setor portuário contribui no processo de crescimento econômico e socioeconômico. Com a crescente produção e exportação de soja e milho no Tocantins, se faz necessário desenvolver e modernizar os meios de transporte para o escoamento dessas produções. Na presente pesquisa foi abordada a situação socioeconômica do município de Porto Nacional, com o objetivo de analisar a implantação de um porto fluvial, pois o mesmo tem um grande potencial de receber e escoar produto agrícola, mineral e combustível. Diante do exposto essa implantação seria um grande indutor de crescimento econômico para esta cidade.

Palavras-chave: Setor portuário; Crescimento socioeconômico; Produção e exportação.

\section{Economic analysis for the implementation of a river port in the municipality of Porto Nacional/TO}

The ports are considered as one of the most important facilities for the national transport infrastructure, with that the port sector contributes to the process of economic and socioeconomic growth. With the growing production and export of soybeans and corn in Tocantins, it is necessary to develop and modernize the means of transport for the transportation of these productions. In this research, the socioeconomic situation of the municipality of Porto Nacional was addressed, with the objective of analyzing the implementation of a river port, as it has a great potential to receive and dispose of agricultural, mineral and fuel products. Given the above, this implementation would be a major driver of economic growth for this city.

Keywords: Port sector; Socioeconomic growth; Production and exports.

Topic: Engenharia Civil

Reviewed anonymously in the process of blind peer
Received: $17 / 12 / 2020$

Approved: 10/03/2021
Ana Luiza Oliveira de Abreu (iD)

Instituto Tocantinense Presidente Antônio Carlos, Brasil

http://lattes.cnpq.br/2330017942159910

http://orcid.org/0000-0002-7318-9639

analuizaoliveiradeabreu@gmail.com
Referencing this:

ABREU, A. L. O.. Analise econômica para implantação de um porto fluvial no município de Porto Nacional/TO. Engineering Sciences, v.9, n.1, p.68-74, 2021. DOI: http://doi.org/10.6008/CBPC23183055.2021.001.0007 


\section{INTRODUÇÃO}

Com o crescimento populacional e econômico do município de Porto Nacional e do estado do Tocantins na área da agricultura e indústrias, é necessária a busca de outro meio de transporte para as exportações dos materiais e produtos que são produzidos, pois os meios convencionais já não estão eficientes como antes.

Nos dias de hoje o transporte marítimo e fluvial vem sendo uma válvula de escape para as exportações e importações de produtos dentro e fora do país. $\mathrm{O}$ avanço tecnológico dos portos fluviais nos últimos anos ocorreu devido ao crescimento econômico do país e a necessidade de exportações, consequentemente, os portos passaram a serem instituições extremamente importantes para o desenvolvimento econômico nacional.

É importante ressaltar, que as atividades portuárias, além de ser fundamental para o equilíbrio da balança comercial do Brasil, é o principal indutor de desenvolvimento dos municípios portuários gerando emprego e renda. E os portos podem receber os benefícios de gerenciar suas operações de maneira eficiente, ecológica e socialmente responsável e além de minimizar a poluição do meio ambiente. 0 estado do Tocantins é banhado pela Bacia do Tocantins - Araguaia, no qual também facilitaria o escoamento da produção agrícola e industrial.

Portanto, visando buscar um meio de transporte que facilitará a comercialização dos produtos e contribuir para o crescimento da economia do município de Porto Nacional e do estado do Tocantins, o presente trabalho teve como objetivo, analisar os dados econômicos do Estado do Tocantins e do Município de Porto Nacional, e verificar quais são os produtos produzidos na região, que possam ser transportados pelo porto fluvial.

\section{REVISÃO TEÓRICA}

O porto é considerado uma junção na cadeia de transporte, contudo sua principal finalidade é promover o desenvolvimento econômico de uma região através do escoamento de pessoas, de bens e de mercadorias e, desse modo movimentar a economia. Tendo como os seus principais objetivos a ascensão do desenvolvimento socioeconômico, romper barreiras, concedendo assim o escoamento e a comercialização de bens e serviços (FALCÃO et al., 2012).

O Porto além de atender a demanda da Cidade, também pode funcionar como um porto central de microrregião do entorno do município, ou seja, recebem passageiros e cargas em pequenas quantidades provenientes de diversas localidades, para então agrupar todos em embarcações maiores com destino aos centros regionais (SANHES, 2008).

As cargas nos portos podem ser classificadas em três tipos: granel sólido, granel líquido e carga geral. Alumina, carvão, minério de ferro, soja, trigo e sal são exemplos de remessas classificadas como granel sólido. Os derivados do petróleo, gases liquefeitos e produtos químicos em geral são considerados granéis líquidos. Produtos diversos, como frutas, produtos agrícolas e carnes são considerados como carga geral. Estes ainda 
têm uma subclassificação, pode ser considerada solta ou conteinerizada (FALCÃO et al., 2012).

A hidrovia do Tocantins-Araguaia é uma das principais hidrovias e a segunda maior bacia do Brasil. Entretanto possui uma área totalizada em $918.243 \mathrm{~km}^{2}$ distribuída pelos estados de Tocantins, Pará, Maranhão, Mato Grosso, Goiás e no Distrito Federal (DNIT, 2018).

Segundo ANA (Agência Nacional das Águas), conforme citado por ANTAQ (Agência Nacional de Transportes Aquaviários) (2013), a hidrovia é coordena pela Administração das Hidrovias do Tocantins e Araguaia (AHITAR). De acordo com as obras de melhoria e viabilidade, a extensão futura dessa hidrovia pode alcançar aproximadamente 3.000 quilômetros, atravessando as regiões Centro-Oeste e Norte do país, ligando o Brasil Central aos portos de Belém (PA) e Vila do Conde (PA), Bacia do Tocantins-Araguaia bem como aos de Itaqui (MA) e Ponta da Madeira (MA) através da Estrada de Ferro Carajás (EFC).

A nascente do Rio Tocantins é situada no Planalto de Goiás, formado pelos rios Almas e Maranhão, tendo $2.400 \mathrm{~km}$ de extensão, até a foz, na Baía de Marajó. Este rio abre espaço para ampliação da fronteira agrícola, principalmente no cultivo de grãos, pois esta região possui grande potencial hidro energético. Tendo como principal afluente o Rio Araguaia. Já o rio Araguaia nasce na Serra do Caiapó, em Goiás, percorre rumo ao Norte por $2.115 \mathrm{~km}$ até desaguar no rio Tocantins, sendo responsável pela divisa natural entre os Estados de Goiás, Mato Grosso, Tocantins e Pará. Este rio possui trechos de leito arenoso e rochosos: os pedrais e os travessões, que podem prejudicar a navegação (DNIT, 2018).

Segundo Portal do Tocantins, com grandes obras estruturantes, o Tocantins possui atrativos que promovem a integração entre os principais eixos de desenvolvimento do País. Aqui, a localização estratégica serve de principal atrativo para grandes empreendedores nacionais e internacionais.

Localizado geograficamente no centro do Brasil e cortado de norte a sul por uma das rodovias federais mais importantes do país, a BR-153 (conhecida nacionalmente como a Belém-Brasília); e pela Ferrovia Norte-Sul, o Tocantins conta ainda com uma malha viária asfaltada de cerca de 8 mil quilômetros, que interliga todos os seus 139 municípios, além das estradas vicinais que possibilitam o transporte dos mais diversos tipos de produtos oriundos, basicamente, do agronegócio (TOCANTINS, 2020).

Em meados de 1738 Porto Real Pontal teve sua origem, onde abrigava o português Felix Camoa, no qual explorava o transporte de passageiros entre as duas margens do rio Tocantins. Por ação do crescente vai e vem de aventureiros de um lado para o outro do rio, ocasionou a comercialização de travessias dos chegantes. Diante disso a população foi crescendo, erguendo um povoado estável em estruturas econômicas e sociais (RODRIGUES, 2017).

O estado do Tocantins atualmente se destaca como uma das economias mais promissoras da região Norte. Obras como a Ferrovia Norte-Sul, a hidrovia Araguaia-Tocantins, o Ecoporto Praia Norte, o Terminal de Cargas (Teca) do Aeroporto de Palmas, a ampla malha asfáltica e as hidrelétricas que fornecem energia para abastecer o Estado e exportar seu excedente, são exemplos de infraestrutura (BRASIL, 2017).

O estado possui 139 municípios que somam 1.383.445 habitantes, de acordo com o censo de 2010 do Instituto Brasileiro de Geografia e Estatística (IBGE). Desse total, 78,81\% da população, o que corresponde a 1.090.241 pessoas, vivem na zona urbana e $21,19 \%$, representando 293.212 pessoas, habitam a zona rural. 
Segundo os últimos dados do IBGE (2010), a taxa de crescimento anual da população tocantinense é de 1,8\%.

Conforme dito pelo Portal do Tocantins, o Estado possui onze distritos agroindustriais em grande expansão, instalados nas cidades-polo de Palmas, Paraíso do Tocantins, Gurupi, Araguaína, Colinas e Porto Nacional. Apresentam estrutura apropriada, contendo energia elétrica, vias asfaltadas e redes de água, tornando-as adequadas para a instalação de diversos tipos de indústrias.

O Produto Interno Bruto (PIB) é o 4으 melhor da região Norte do País e ocupa o 24 ㅇ lugar no ranking nacional. Em relação à taxa de crescimento anual, o Estado ocupa o primeiro lugar do ranking. Enquanto a média da taxa de crescimento nacional foi de 27,5\% entre 2002 e 2009, e o Norte do País alcançou 39,3\%, o Tocantins foi ainda mais longe, registrando média de 52,6\% nos últimos oito anos (BRASIL, 2017).

Porto Nacional tem uma população estimada em 2019 de quase 53.010 mil pessoas com PIB per capita de R\$4 49.738,85 mil, e o IDHM índice de desenvolvimento humano municipal é de 0,740, o que é considerado alto (IBGE, 2010).

Porto Nacional foi o Município do Estado que mais evoluiu em empregos formais entre as cidades com mais de 30 mil habitantes. O desempenho registrou uma variação de 1,03\%, mesmo com a crise econômica nacional, que atinge boa parte dos Municípios, Porto Nacional se destaca com planejamento estratégico e incentivo às atividades econômicas (RAMOS, 2018).

\section{METODOLOGIA}

O presente projeto foi realizado na cidade de Porto Nacional, Estado do Tocantins, com o objetivo de fazer a análise socioeconômica do município supracitado no estado do Tocantins.

A pesquisa foi quali-quantitativa para determinar os tipos de usuários e produtos que poderão se beneficiar com a construção de um porto fluvial.

Foi analisado o perfil socioeconômico do Estado do Tocantins e do Município de Porto Nacional, visualizando as indústrias que poderão utilizar o porto, para o transporte dos seus produtos. Essas informações serão extraídas através de sites de pesquisas, jornais e artigos.

Os dados socioeconômicos do Município Porto Nacional e do Estado do Tocantins, foram, realizados no site da prefeitura Municipal, no IBGE (Instituto Brasileiro de Geografia e Estatística), e na SEFAZ (Secretaria da Fazenda do Tocantins), Portal do Tocantins.

Com todos os dados obtidos verificamos a viabilidade da implantação do porto fluvial no Município de Porto Nacional, sendo esse fazendo a intermodalidade com a Ferrovia Norte-Sul, realizando o escoamento dos produtos produzidos no Estado do Tocantins.

\section{RESULTADOS E DISCUSSÃO}

Atraves dos estudos realizados, observamos que a economia do Estado do Tocantins vem crescendo a cada ano que se passa, o comercio, as industrias e a produção agricola vem se destacando neste cenário economico, conforme mostrado na Figura 1. 


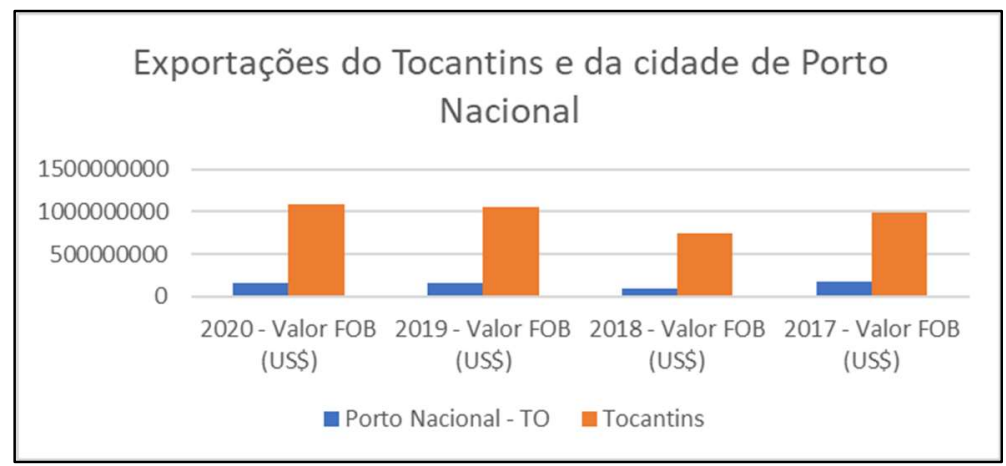

Figura 1: Exportações do Tocantins e do Município de Porto Nacional.

De acordo com o último censo do IBGE realizado no ano de 2017, o PIB (Produto Interno Bruto) do Estado do Tocantins foi em torno dos 34 milhões, tendo um crescente anual de 3,1 \%. Já o Município Porto Nacional ficou entre as três cidades do Estado que mais cresceram no PIB de 2017, com um aumento de $71,9 \%$.

O Estado do Tocantins é um grande produtor agrícola, com destaque para o cultivo de arroz, mandioca, cana-de-açúcar, milho e, principalmente, soja. O seu setor industrial está concentrado nas cidades de Palmas, Gurupi, Porto Nacional, Araguaína e Paraíso do Tocantins.

Devido ao clima favorável, a abundância de água, energia, logística de escoamento e novas tecnologias que vem surgindo, o setor do agronegócio vem tendo grande crescimento na sua produção.

A expansão das áreas de produção de soja, e a chegada de grandes empresas multinacionais no Município de Porto Nacional, acarretou em uma grande expansão de sua economia. Dentre essas grandes empresas instaladas no município podemos destacar a Granol, Bunge, Fiagril, Cargril, Miltigrain, etc.

De acordo com a Companhia Nacional de Abastecimento (CONAB, 2020) mostra que o crescimento nos últimos 10 anos obteve aumento superior a 185\% na produção de grãos, saltando de 1,86 milhão de toneladas, na safra 2009/2010, para mais de 5,3 milhões de toneladas, safra 2019/2020 (produção estimada).

Conforme a Secretaria de Agricultura Pecuária e Aquicultura (SEAGRO, 2016), o Tocantins se destaca como o maior produtor de grãos da região Norte do Brasil, sobretudo de soja, arroz, milho e feijão. Outros produtos que também está em crescimento no estado é o cultivo de frutas tropicais, em especial a melancia, o abacaxi e a banana.

Segundo a balança comercial do Tocantins, Porto Nacional se sobressaiu entre os Municípios Tocantinense, como maior exportador, num total de US\$ 178 milhões, tendo um aumento de $18 \%$ de participação no volume exportado em 2017 com um crescimento de 109,65\%, em relação aos anos anteriores. Este crescimento ocorreu devido ao aumento nas exportações de Soja $(395,39 \%)$ e Milho (631,04\%) (BRASIL, 2017).

O Estado do Tocantins também é grande produtor agrícola, com destaque para o cultivo de arroz, mandioca, cana-de-açúcar, milho e, principalmente, soja. O setor industrial está concentrado nas cidades de Palmas, Gurupi, Porto Nacional, Araguaína e Paraíso do Tocantins.

Como podemos analisar no gráfico 2 , a soja é o principal produto exportado pelo Tocantins, e representa 70\% de todas as exportações do estado, gerando em receita no ano de 2019 um valor de US\$773 
milhões. Já no ano de 2020 a soja obteve um crescimento de 32,2\% no primeiro trimestre, superando assim as expectativas dos produtores.

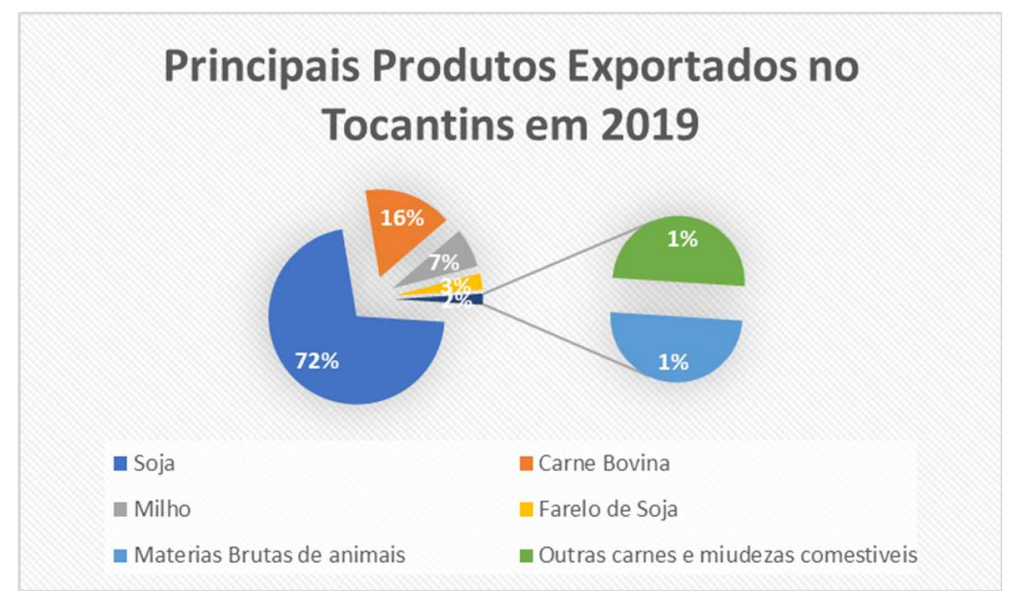

Figura 2: Principais produtos Exportados no Tocantins em 2019.

No Tocantins houve um acréscimo de 19,2\% na plantação do milho, com aumento na produtividade, em torno de 3,4\%. Os produtores chegaram a colher mais de $7.200 \mathrm{~kg} / \mathrm{ha}$ nas primeiras áreas semeadas, demonstrando grande potencial das lavouras no estado. A produtividade média atingiu $5.084 \mathrm{~kg} / \mathrm{ha}$, crescimento de 3,4\%, comparada com a última safra, devido ao plantio dentro da janela e às condições climáticas favoráveis (CONAB, 2020).

A produção de arroz no Tocantins foram 122,7 mil hectares plantados na safra de 2019/2010, perfazendo uma produção de 660 mil toneladas, incremento de 5,8\% em relação ao volume obtido em 2018/19 (CONAB, 2020).

O agronegócio Brasileiro segue em grande alta, o PIB do agronegócio brasileiro seguiu avançando em julho, com crescimento de 1,26\%, segundo cálculos do Cepea (Centro de Estudos Avançados em Economia Aplicada), da Esalq/USP, realizados em parceria com a CNA (Confederação da Agricultura e Pecuária do Brasil). Com isso, o PIB do agronegócio brasileiro amplia o crescimento para fortes 6,75\% na parcial do ano de 2020 no período de janeiro a julho.

Analisando a logística de escoamento dos produtos produzidos no Estado do Tocantins e no Município de Porto Nacional, verifica que a Ferrovia Norte-Sul se constitui num importante meio de escoamento da produção de mercadorias, na qual poderá atender o Porto Fluvial assim permitindo agilidade na exportação dos produtos as demais regiões.

\section{CONCLUSÕES}

Com base nas pesquisas realizadas, a análise socioeconômica do Estado do Tocantins e do Município de Porto Nacional foi de suma importância para determinar o quanto a economia do Estado quanto do Município teve um crescimento significante nos últimos anos, isso devido ao grande desenvolvimento do setor do agronegócio.

O desenvolvimento do estudo permitiu apurar o quanto a produção agrícola está impulsionando a economia do Estado do Tocantins e do Município de Porto Nacional, com destaque para a produção de soja 
e milho, no qual são os produtos mais produzidos na região.

Dada a importância ao assunto, a implantação de um Porto Fluvial para fazer o escoamento dos produtos é uma grande vantagem, pois reduziria os custos logísticos para as empresas que irão exportar seus produtos, impulsionaria ainda mais a economia da região, e seria um modal muito importante para fazer a intermodalidade com a Ferrovia Norte-Sul, que passa pelo Município de Porto Nacional, assim impulsionando as exportações dos produtos.

\section{REFERÊNCIAS}

ANTAQ. Agência Nacional de Transporte Aquaviários. Desenvolvimento de Estudos e Análises das Hidrovias Brasileiras e suas Instalações Portuárias com Implantação de Base de Dados Georreferenciada e Sistema de Informações Geográficas. ANTAQ, 2013.

BRASIL. Secretaria da Agricultura, Pecuária e Aquicultura. Agricultura. Palmas: SEAGRO, 2016.

BRASIL. Secretaria da Fazenda e Planejamento. PIB Municipal. Palmas: SEFAZ, 2017.

BRASIL. Secretaria da Fazenda e Planejamento. Produto Interno Bruto do Tocantins. Palmas: SEFAZ, 2017.

CONAB. Companhia Nacional de Abastecimento. Acompanhamento da Safra Brasileira de grãos. CONAB, 2020.

DNIT. Departamento Nacional de Infraestrutura e Transporte. Hidrovia do Tocantins: Araguaia. DNIT, 2018.

FALCÃO, V. A.; CORREIA, A. R.. Eficiência portuária: análise das principais metodologias para o caso dos portos brasileiros. Journal of Transport Literature, Manaus, v.6, n.4, p.133-146, 2012.

IBGE. Instituto Brasileiro de Geografia e Pesquisa. Porto Nacional. IBGE, 2010.

RAMOS, P.. Economia: Porto Nacional lidera criação de empregos no Estado; Produção agrícola do Município é destaque. Porto Nacional: Secom, 2018.

RODRIGUES, E.. Um breve histórico sobre a fundação e emancipação política de Porto Nacional. Prefeitura de Porto Nacional, 2017.

SANHES, R. A.. Projeto de Portoas no Amazonas. São Paulo: Centro Universitário Luterano de Manaus, 2008.

TOCANTINS. Diretoria de Indústria, Comércio e Serviços. Logística. Palmas: SICS, 2020.

A CBPC - Companhia Brasileira de Produção Científica (CNPJ: 11.221.422/0001-03) detém os direitos materiais desta publicação. Os direitos referem-se à publicação do trabalho em qualquer parte do mundo, incluindo os direitos às renovações, expansões e disseminaçães da contribuição, bem como outros direitos subsidiários. Todos os trabalhos publicados eletronicamente poderão posteriormente ser publicados em coletâneas impressas sob coordenação da Sustenere Publishing, da Companhia Brasileira de Produção Científica e seus parceiros autorizados. Os (as) autores (as) preservam os direitos autorais, mas não têm permissão para a publicação da contribuição em outro meio, impresso ou digital, em português ou em tradução. 